\title{
BMJ Open Association between psychosocial distress, sexual disorders, self-esteem and quality of life with male androgenetic alopecia: a population- based study with men at age 46
}

Suvi-Päivikki Sinikumpu (D) , ${ }^{1,2}$ Jari Jokelainen, ${ }^{3}$ Juha Auvinen, ${ }^{4}$ Markku Timonen, ${ }^{4}$ Laura Huilaja ${ }^{1,2}$

To cite: Sinikumpu S-P, Jokelainen J, Auvinen J, et al. Association between psychosocial distress, sexual disorders, self-esteem and quality of life with male androgenetic alopecia: a population-based study with men at age 46. BMJ Open 2021;11:e049855. doi:10.1136/ bmjopen-2021-049855

- Prepublication history for this paper is available online To view these files, please visit the journal online (http://dx.doi. org/10.1136/bmjopen-2021049855).

Received 05 February 2021 Accepted 16 December 2021

Check for updates

(c) Author(s) (or their employer(s)) 2021. Re-use permitted under CC BY-NC. No commercial re-use. See rights and permissions. Published by BMJ.

For numbered affiliations see end of article.

Correspondence to Dr Suvi-Päivikki Sinikumpu; suvi-paivikki.sinikumpu@oulu.fi

\section{ABSTRACT}

Objectives To study the association between androgenetic alopecia (AGA) and its severity with psychosocial well-being in male subjects aged 46 years at the population level.

Design Cross-sectional study.

Setting The Northern Finland Birth Cohort 1966 (NFBC1966).

Participants Data were available for 892 male subjects aged 46 years.

Interventions Study subjects underwent comprehensive health examinations including a skin evaluation by dermatologists and determination of AGA according to the Norwood classification. They also filled in a questionnaire battery that included previously validated questionnaires: the Hopkins Symptom Checklist-25, the Beck Depression Inventory-II; the Generalised Anxiety Disorder Screener; a 15-dimensional measure of health-related quality of life; a 12-Item General Health Questionnaire. The battery also included questions about self-esteem and sexual health. Main outcome measurements The presence of AGA and its severity, psychosocial well-being.

Results AGA was found in $68.5 \%$ of subjects, $27.8 \%$ of the cases were severe, $33.2 \%$ moderate and $39.0 \%$ mild. There was no significant association between the presence of AGA or its severity with depression, anxiety, quality of life, self-esteem or sexual symptoms. Those with severe AGA reported lower sexual activity when compared with those without AGA; however, the difference was not statistically significant.

Conclusions Middle-aged men with AGA did not differ from men without AGA in terms of psychosocial well-being.

\section{INTRODUCTION}

Androgenetic alopecia (AGA) is the most common type of hair loss in men. ${ }^{1}$ The incidence of AGA increases by age and affects up to $50 \%$ of all men by age 50 and $80 \%$ by age $80 .{ }^{2}$ Its prevalence is highest in the Caucasian population. ${ }^{3}$ The aetiology of AGA is multifactorial, but genetic predisposition and hormonal status are particularly prominent. ${ }^{4}$
Strengths and limitations of this study

- To our knowledge, this is the first study to assess the association between androgenetic alopecia and psychosocial well-being in a large, unselected general population.

- Androgenetic alopecia was diagnosed and classified by dermatologists instead of self-reporting.

- Psychosocial well-being was evaluated from diverse viewpoints by using comprehensive, previously standardised questionnaires.

- Study subjects represent only a middle-age population and thus our findings cannot be generalised to other age groups, such as younger males.

- In previous studies selection bias may have led to offer a flawed impression of the association between androgenetic alopecia and psychosocial well-being.

AGA may begin shortly after puberty but more commonly has later onset. ${ }^{3}$ The severity of AGA varies from minor hair loss in the temporal area to complete loss of hair from the entire scalp.

AGA has a significant impact on quality of life (QoL). ${ }^{5-7}$ Subjects with AGA have reported elevated levels of body image distress and social self-consciousness, loss of self-esteem, decreased feelings of well-being and impaired QoL. ${ }^{8-10}$ Furthermore, AGA is associated with psychological disorders and symptoms like anxiety, somatisation and depression. ${ }^{5} 611{ }^{12}$ In addition, impaired sexual function has been documented in subjects with AGA. ${ }^{10} 13$

Psychological features are particularly related to severe hair loss and younger age of onset. ${ }^{14}$ A Chinese study group evaluated the psychological symptoms of AGA by using interviews and psychological questionnaires among 761 college students $(n=355$ with 
AGA) and found that AGA was associated with various psychological problems. ${ }^{12}$ Decreased QoL was found in AGA patients who were referred to a dermatologic clinic in India (mean age 32 years, $\mathrm{n}=200)^{8}$ and the same effect was seen in a multicentre study $(\mathrm{n}=998)$ performed in dermatological clinics in Korea. ${ }^{14}$ Both these studies found that QoL was particularly lowered in patients with earlier AGA onset or more severe hair loss. ${ }^{12} 14$

Many previous studies report AGA to be a very stressful condition with several psychosocial comorbidities. ${ }^{5} 6$ However, most have focused on moderately young participants or are limited to special population subgroups, either of which may have caused bias. ${ }^{5-8} 14$ To the best of our knowledge, the association between AGA and psychosocial effects has not previously been studied in a large, unselected general population. We wanted to study whether the presence of AGA is associated with psychosocial well-being in an unselected population of middleaged men at the age of 46 years. We therefore designed the present study, which uses data from the Northern Finland Birth Cohort 1966 (NFBC1966) Study to examine the effects of AGA and its severity on the prevalence of psychological, social and sexual symptoms.

\section{METHODS}

\section{Study population}

The study population is a subset of the NFBC1966 which is a longitudinal research programme. The NFBC1966 initially included all 12058 children in the two northernmost provinces of Finland whose expected dates of birth fell in the year 1966 (covered 48\% of Finnish territory and $13.2 \%$ of population in 1966). ${ }^{15}$ The whole cohort has been evaluated regularly since birth by means of health questionnaires and clinical examinations. At the age of 46 years, all cohort members living in the city of Oulu and its surroundings ( $100 \mathrm{~km}$ distance including rural areas) were invited to the comprehensive health study including several clinical examinations (eg, dermatological evaluation) and health questionnaires (including psychosocial evaluation). The 46-year follow-up study was performed between April 2012 and May 2013 and cohort members were $45-47$ years of age at this stage.

\section{Assessment of hair loss}

Full dermatological status was comprehensively determined for all the subjects by the dermatologist or experienced resident. ${ }^{16}$ All study subjects were categorised by presence/severity of AGA, as determined by their score on the international Norwood classification system ${ }^{17}$ as follows: (0) no hair loss (Hamilton-Norwood (HN)) scale I), (1) frontal baldness only (HN scale II-IIIa), (2) frontal hair loss with mild vertex baldness (HN scale IIIvertex V), (3) frontal hair loss with moderate vertex baldness (HN scale VI) and (4) frontal hair loss with severe vertex baldness (HN scale VII). AGA was then classified to four groups according to its severity during clinical examination; without AGA (HN I), mild AGA (HN II-III), moderate AGA (HN III vertex-HN VI) and severe AGA (HN VII).

\section{Psychological questionnaires}

Hopkins Symptom Checklist-25 (HSCL-25)

Participants were screened for common psychiatric symptoms using the HSCL-25. ${ }^{18-20}$ An individual's total score is calculated as the mean score of all 25 items ranging from 1.00 to 4.00 . A high total score is shown to be highly correlated with severe emotional distress. ${ }^{18} 19$ Commonly used cut-off points $\geq 1.55$ and $\geq 1.75$ were also used in the present study to indicate the presence of psychiatric disorder. ${ }^{21} 22$

\section{Self-reported history of depression}

Previously diagnosed depression or depressive symptoms was recorded by subjects' response to the question: 'Have you ever been diagnosed with/treated for depression/ depressive symptoms by a physician?'

\section{Beck Depression Inventory-II (BDI-II)}

Current depression was assessed using the BDI-II. The present analysis used total scores of $\geq 14$ and $\geq 20$ to define the presence of depressive symptoms. ${ }^{23}$ The summary score of the melancholic dimension of the BDI-II was used to subdivide with more frequent melancholic symptoms from those with non-melancholic symptoms. ${ }^{2425}$

\section{Generalised Anxiety Disorder Screener (GAD-7)}

The GAD-7 was used as a measure of GAD, with a cut-off score of 10 to define subject as having GAD (<10 mild/ moderate; $>10$ severe) ${ }^{26}$

The 15-dimensional measure of health-related quality of life (15D $\mathrm{HRQOL})$

The 15-D questionnaire is a generic, standardised, well-validated, self-administered measure of HRQoL. ${ }^{27}$ Possible total scores range between 0 and 1 , with an index value of 1 representing full health, and 0 equivalent to death. $^{28}$

\section{2-item General Health Questionnaire (GHQ-12)}

Psychological distress was measured by the 12-item version of Goldberg's GHQ-12, which was developed to screen for non-specific psychiatric morbidity in populations. ${ }^{29}$ The responses to individual items are summed to yield a total score varying from 0 to 12 . The overall sum of the 12 items was used to categorise study subjects, with $0-2$ points indicating 'no distress' and $\geq 3$ points indicating psychological distress. ${ }^{30}$

\section{Self-esteem}

The self-esteem of cohort subjects was assessed by following questions: 'I feel accepted and welcomed. I have a feeling that I am a good and valuable person', 'I am seen as a competent and capable person', 'When I look into a mirror, I see a good person.' 'I am proud of my roots and background'. All questions were scored on a scale ranging between 0 and 10 where 0 meant 'never' 
and 10 'constantly'. The responses were summed and the mean value of scores was recorded.

\section{Sexual questions}

The sexual health of study subjects was evaluated using the following questions: 'Frequency of days in which morning erection occurred' ( $\geq 2$ times in a week; once a week, 2-3 times a month, once a month; never), 'Do you have difficulties in sexual intercourse?' (Yes/No), 'How often do you have thoughts of sexual intercourse?' (Never; once a month; once a week, 2-3 times in a week; daily), 'What is the frequency of sexual intercourse?' (Never; once a month; once a week, 2-3 times in a week; daily).

\section{Education}

The study subjects were classified into three subgroups of education: basic education, secondary and tertiary education. ${ }^{16}$ The information about education level was obtained from the Finnish National Education Register ${ }^{31}$ and was supplemented with responses from self-reported questionnaires. The information on marital status was self-reported.

\section{Patient and public involvement}

No patients were involved in setting the research question, or in developing plans for recruitment, design, implementation and dissemination of the results of this study.

\section{Statistical analyses}

Continuous variables are presented as means and SD or as medians (25\% and $75 \%$ quartiles) and categorical variables are presented as the number and percentage of subjects in each category. For categorical variables, Pearson's $\mathrm{X}^{2}$ test was used to identify any differences in proportions between categorical variables. The differences in distribution of clinical characteristics were tested using analysis of variance (ANOVA). Values of $\mathrm{p}<0.05$ were considered statistically significant.

\section{RESULTS}

In connection with the 46-year follow-up survey of the whole birth cohort, 3181 cohort members were invited to undergo a dermatological examination. Of these, 1932 (60.7\%) participated, including 892 men (46.2\%), who comprised the population of the present analysis. The mean (SD) age of men at the time of the skin study was $46.4(0.4)$, with a range of $45.3-47.6$ years.

The baseline characteristics of the study population according to the AGA classification are presented in table 1. AGA was present in $611(68.5 \%)$, with $27.8 \%$ of those having severe AGA, 33.2\% moderate and $39.0 \%$ mild. Table 2 summarises the percentage distribution of AGA in subgroups defined by the above-mentioned psychosocial measures. As shown in table 2, there was no significant association between the presence of AGA and psychosocial symptoms. Furthermore, no association was found between AGA severity and the aforementioned symptoms. Study subjects with severe AGA reported lower sexual activity when compared with those without AGA; however, the difference was not statistically significant $(\mathrm{p}>0.05)$.

\section{DISCUSSION}

To our knowledge, the psychosocial effects of AGA have not been previously analysed in a general population. Based on the use of diverse standardised questionnaires, we found that AGA had no effect on the psychosocial well-being of this group of middle-aged men at the age of 46 years.

Subjects with AGA have previously been described to more frequently exhibit avoidant personality traits, anxiety and depression than those without hair loss. ${ }^{5} 6$ Interestingly, the findings of the present study differ markedly from those of previous reports. In a recent singlecentre study by Tas and co-authors $(n=353)$, the risk for psychosexual symptoms was reported to increase with the severity of hair loss. ${ }^{10}$ Similarly, QoL was found to be lower

Table 1 Demographics of study population according to androgenetic alopecia (AGA) classification

\begin{tabular}{|c|c|c|c|c|c|c|}
\hline & (ALL) & Without AGA & Mild AGA & Moderate AGA & Severe AGA & \\
\hline & $\mathrm{N}=892$ & $\mathrm{~N}=\mathbf{2 8 1}$ & $\mathrm{N}=238$ & $\mathrm{~N}=\mathbf{2 0 3}$ & $\mathrm{N}=170$ & $P$ value \\
\hline Marital status & & & & & & 0.120 \\
\hline Single & $173(20.0 \%)$ & 54 (19.9\%) & 37 (16.1\%) & 38 (19.6\%) & $44(26.3 \%)$ & \\
\hline Widower & $1(0.12 \%)$ & $1(0.37 \%)$ & $0(0.00 \%)$ & $0(0.00 \%)$ & $0(0.00 \%)$ & \\
\hline Basic & 30 (3.36\%) & $11(3.91 \%)$ & $6(2.52 \%)$ & $10(4.93 \%)$ & $3(1.76 \%)$ & \\
\hline Secondary & $535(60.0 \%)$ & $167(59.4 \%)$ & $143(60.1 \%)$ & $112(55.2 \%)$ & $113(66.5 \%)$ & \\
\hline Tertiary & 327 (36.7\%) & 103 (36.7\%) & 89 (37.4\%) & 81 (39.9\%) & 54 (31.8\%) & \\
\hline
\end{tabular}

${ }^{*}$ Basic education (comprehensive schools), secondary level (upper secondary schools, vocational schools), tertiary level (universities, polytechnics). 
Table 2 The association between androgenetic alopecia and psychological symptoms

\begin{tabular}{|c|c|c|c|c|c|}
\hline & Without AGA & Mild AGA & Moderate AGA & Severe AGA & \\
\hline & $\mathrm{N}=\mathbf{2 8 0}+$ & $\mathrm{N}=\mathbf{2 3 5 \dagger}$ & $\mathrm{N}=201 \dagger$ & $\mathrm{N}=169+$ & P value* \\
\hline 15D HRQoL score (mean, SD) & $0.93(0.08)$ & $0.94(0.06)$ & $0.94(0.06)$ & $0.94(0.06)$ & 0.271 \\
\hline HSCL25 score (mean, SD) & $1.31(0.34)$ & $1.29(0.29)$ & $1.28(0.27)$ & $1.30(0.35)$ & 0.666 \\
\hline HSCL25 score categories & & & & & 0.679 \\
\hline$<1.55$ & $215(82.1 \%)$ & $191(85.7 \%)$ & $152(83.1 \%)$ & $128(81.5 \%)$ & \\
\hline$\geq 1.55$ & 47 (17.9\%) & $32(14.3 \%)$ & $31(16.9 \%)$ & $29(18.5 \%)$ & \\
\hline HSCL25 score categories & & & & & 0.264 \\
\hline$<1.75$ & $236(90.1 \%)$ & 206 (92.4\%) & $171(93.4 \%)$ & $138(87.9 \%)$ & \\
\hline$\geq 1.75$ & $26(9.92 \%)$ & $17(7.6 \%)$ & $12(6.6 \%)$ & $19(12.1 \%)$ & \\
\hline BDI II, mean (SD) & $5.29(6.25)$ & $4.70(5.11)$ & $5.11(5.72)$ & $4.87(5.53)$ & 0.684 \\
\hline Melancholic symptoms & $2.83(3.11)$ & $2.41(2.44)$ & $2.66(2.87)$ & $2.53(2.87)$ & 0.404 \\
\hline Non-melancholic symptoms & $2.55(3.61)$ & $2.30(2.88)$ & $2.45(3.05)$ & $2.33(2.89)$ & 0.809 \\
\hline Neurovegetative function & $0.37(0.39)$ & $0.32(0.32)$ & $0.34(0.34)$ & $0.32(0.33)$ & 0.468 \\
\hline Mood & $0.16(0.31)$ & $0.14(0.23)$ & $0.14(0.23)$ & $0.14(0.23)$ & 0.643 \\
\hline Negative affect & $0.17(0.32)$ & $0.14(0.25)$ & $0.17(0.29)$ & $0.16(0.28)$ & 0.606 \\
\hline BDI II score categories & & & & & 0.560 \\
\hline$<14$ & $236(91.5 \%)$ & $214(93.9 \%)$ & $176(90.3 \%)$ & $150(92.6 \%)$ & \\
\hline$\geq 14$ & $22(8.5 \%)$ & $14(6.1 \%)$ & $19(9.7 \%)$ & $12(7.4 \%)$ & \\
\hline BDI II score categories & & & & & 0.430 \\
\hline$<20$ & $247(95.7 \%)$ & $224(98.2 \%)$ & $189(96.9 \%)$ & $158(97.5 \%)$ & \\
\hline$\geq 20$ & $11(4.3 \%)$ & $4(1.8 \%)$ & $6(3.1 \%)$ & $4(2.5 \%)$ & \\
\hline $\begin{array}{l}\text { Self-esteem, mean (SD) } \\
\text { 'I feel accepted and welcomed. I have a feeling that I } \\
\text { am a good and valuable person' }\end{array}$ & $7.88(1.71)$ & $8.12(1.56)$ & $7.97(1.50)$ & $7.83(1.88)$ & 0.361 \\
\hline 'I am seen as a competent and capable person' & $8.03(1.42)$ & $8.20(1.42)$ & $8.06(1.37)$ & $7.84(1.65)$ & 0.144 \\
\hline 'When I look into a mirror, I see a good person.' & $7.69(1.73)$ & $7.85(1.62)$ & $7.72(1.75)$ & $7.61(1.79)$ & 0.619 \\
\hline 'I am proud of my roots and background' & $8.23(1.64)$ & $8.16(1.70)$ & $7.91(1.88)$ & $8.06(2.00)$ & 0.307 \\
\hline GAD7 score (mean, SD) & $2.22(3.20)$ & $1.79(2.59)$ & $2.05(2.71)$ & $2.04(3.01)$ & 0.502 \\
\hline GAD7 score categories & & & & & 0.581 \\
\hline$<10$ & $219(96.9 \%)$ & $201(97.6 \%)$ & $180(98.9 \%)$ & $138(97.2 \%)$ & \\
\hline$\geq 10$ & $7(3.1 \%)$ & $5(2.4 \%)$ & $2(1.1 \%)$ & $4(2.8 \%)$ & \\
\hline $\begin{array}{l}\text { Sexual health } \\
\text { Frequency of erections }\end{array}$ & & & & & 0.070 \\
\hline Never & $12(4.4 \%)$ & $9(4.0 \%)$ & $6(3.01 \%)$ & $10(6.1 \%)$ & \\
\hline Once a month & $39(14.4 \%)$ & $23(10.1 \%)$ & $28(14.4 \%)$ & $15(9.20 \%)$ & \\
\hline 2-3 times a month & $34(12.6 \%)$ & $29(12.8 \%)$ & $32(16.5 \%)$ & $38(23.3 \%)$ & \\
\hline Once a week & $59(21.9 \%)$ & $48(21.1 \%)$ & $40(20.6 \%)$ & $39(23.9 \%)$ & \\
\hline$\geq 2$ times a week & $126(46.7 \%)$ & $118(52.0 \%)$ & $88(45.4 \%)$ & $61(37.4 \%)$ & \\
\hline Problems with sexual intercourse & & & & & 0.933 \\
\hline No & $238(87.8 \%)$ & $203(88.3 \%)$ & $171(88.1 \%)$ & $150(89.8 \%)$ & \\
\hline Yes & $33(12.2 \%)$ & $27(11.7 \%)$ & $23(11.9 \%)$ & $17(10.2 \%)$ & \\
\hline How often do you have thoughts of sex intercourse? & & & & & 0.298 \\
\hline Never & $3(1.1 \%)$ & $3(1.3 \%)$ & $0(0.00 \%)$ & $4(2.4 \%)$ & \\
\hline Once a month & $5(1.8 \%)$ & $5(2.2 \%)$ & $3(1.6 \%)$ & $2(1.2 \%)$ & \\
\hline Once a week & $24(8.82 \%)$ & $29(12.8 \%)$ & $25(13.0 \%)$ & $16(9.70 \%)$ & \\
\hline 2-3 times a week & $103(37.9 \%)$ & $71(31.3 \%)$ & 79 (40.9\%) & $70(42.4 \%)$ & \\
\hline
\end{tabular}




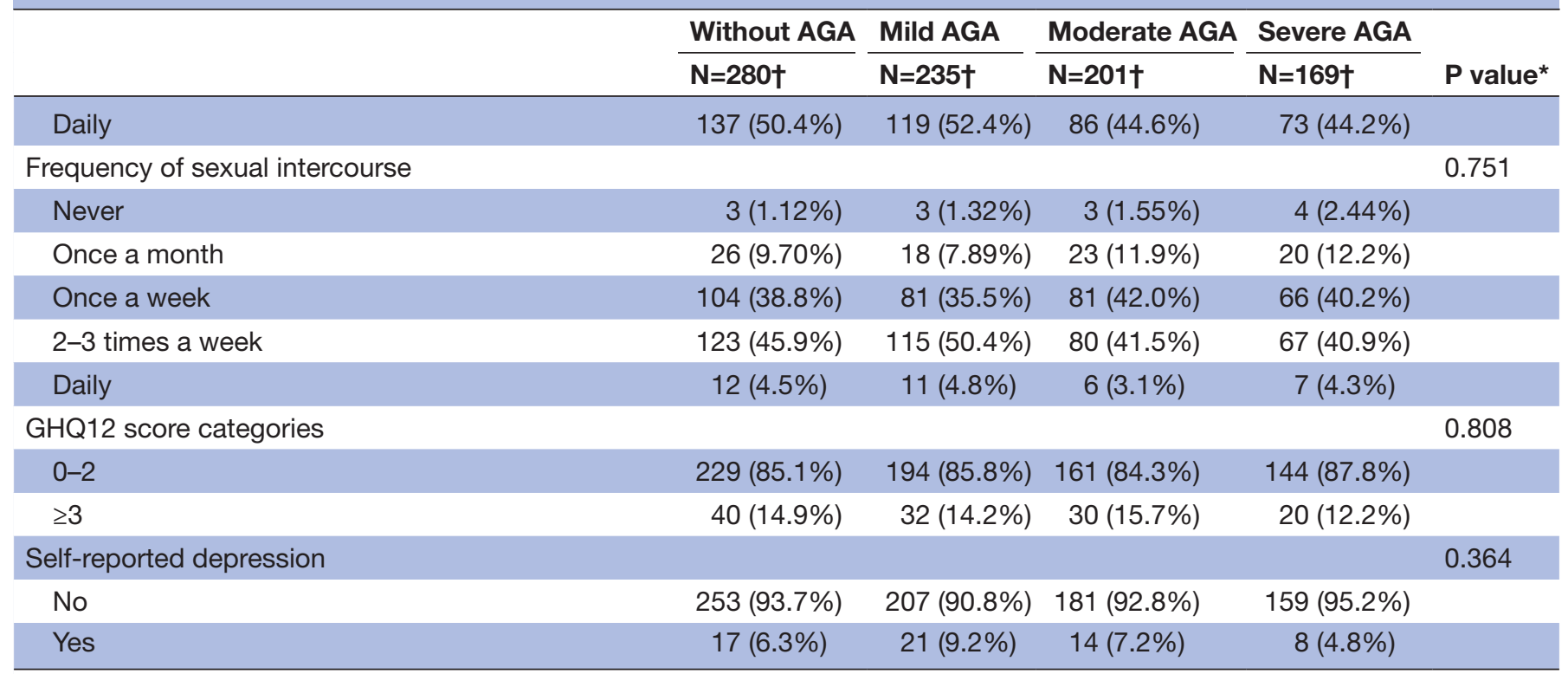

Data are presented as $\mathrm{n}(\%)$ unless otherwise specified.

${ }^{*} P$ value was calculated by using Pearson's $X^{2}$ test or analysis of variance.

†There is some missing data because all study cases did not answer to the questionnaires or denied the use of data afterwards.

BDI II, Beck Depression Inventory version II; 15D HRQoL, 15D instrument of health-related quality of life; GAD7, Generalised Anxiety Disorder

7-item instrument; GHQ12, 12-item General Health Questionnaire; HSCL25, the 25-item Hopkins Symptoms Checklist.

in subjects with AGA when compared with those without AGA in a multicentre study performed in Korea $(n=998) .{ }^{14}$ This finding was confirmed by an Indian study of 200 men with AGA; in that study QoL was inversely correlated with AGA severity. ${ }^{8}$ However, those studies may have been subject to bias through their use of selected populations (collected from dermatology clinics or trichology clinics). It is very likely that those seeking help for hair loss might have had difficulties in accepting changes in their appearance, and consequently, might have had an elevated risk of associated psychosocial symptoms.

In the present study, psychosocial well-being was evaluated from diverse viewpoints by using comprehensive, previously standardised questionnaires. The study by Tas et al employed a partially comparable psychological test battery. ${ }^{10}$ That study found that psychosocial symptoms increased with the severity of hair loss, but it addressed only severity of hair loss and failed to address differences between subjects with normal hair status and those with AGA. A comprehensive battery of psychological measurements was also used in the study by Cash. ${ }^{6}$ They reported that hair loss is an unwanted and distressing experience. ${ }^{6}$ However, the subjects were recruited to the study through barber shops and hair salons, which may have led to selection bias. The study by Gupta et al, which used the widely known and standardised Dermatology Life Quality Index, found life satisfaction to be lower in subjects with hair loss, ${ }^{8}$ but in the context of their cohort, study cases were recruited from a dermatology clinic which can be considered unrepresentative of the general population.
One explanation for how our results diverge from those of previous studies could be methodological differences. A large study of 1707 men aged 18-40 years conducted in four countries (France, Germany, Italy and the UK) reported that hair loss had a significant negative effect on many aspects of the subjects' lives, including diminished life satisfaction, a greater degree of bother and more concern about growing older. ${ }^{7}$ However, this study used questionnaires that were specifically concerned with hair loss. In turn, our study had no such direct link to hair loss, which likely made for a more objective evaluation (questionnaires were part of the 46-year collection of birth cohort). Another, smaller study similarly hid the purpose of data collection from the subjects. ${ }^{13}$ In that study, investigators reported that the increasing degree of hair loss was associated, for example, with low self-esteem and depression. ${ }^{13}$ However, a lack of detailed description of the methods of data collection, coupled with incomplete clarity regarding the sample size ${ }^{13}$ make it difficult to compare that study with ours.

The main strength of our study was the coverage of a wide general population. To the best of our knowledge, the relationship between AGA and psychosocial wellbeing has not previously been studied in such large and unselected population. The participation rate was satisfactory good $(60.9 \%)$ which is highly comparable with the participation rates in other cross-sectional European health examination surveys. ${ }^{32} 33$ Another major strength of the study is that AGA was diagnosed and classified by dermatologists, who have optimal ability to differentiate AGA from other conditions that cause hair loss. Many 
previous studies have used self-evaluation in grading hair loss, a method that can easily lead to underestimation. It is also noteworthy that our study subjects were not asked to commit to the this study because of their hair loss; this markedly differentiates our study from many previous studies of AGA. ${ }^{571434}$ We admit some limitations of the present study. Our study subjects represent only a Caucasian middle-age population at the of 46 years and thus our findings cannot be generalised to other age groups, such as younger males, in whom AGA is even more likely to be associated with psychosocial problems. ${ }^{11} 1314$ Since our study was not longitudinal, it does not exclude the possibility of developing these symptoms, perhaps with greater cumulative exposure to AGA, over time. It is also possible that men in our study have already tended to come to terms with their AGA. Furthermore, as another limitation we admit that not all invited cohort members participated in the study, which may have led to some bias. In the 46-year follow-up study, participants were more often employed and from higher social class, more likely married and with children when compared with non-participants. ${ }^{33}$

\section{Conclusions}

AGA affects most men at some point in adult life. Thus, it is not surprising that the relationship between AGA and well-being has been widely studied. However, selection bias may have led previous studies to offer a flawed impression of this phenomenon. We found that AGA was not associated with psychosocial problems at the age of 46 years. However, more population-based studies are needed to confirm our finding. It would be especially interesting to see studies of similar design among younger males with AGA.

\section{Author affiliations}

${ }^{1}$ Department of Dermatology, Oulu University Hospital, Oulu, Finland ${ }^{2}$ PEDEGO Research Group, Medical Research Center, University of Oulu, Oulu, Pohjois-Pohjanmaa, Finland

${ }^{3}$ Northern Finland Birth Cohorts, Arctic Biobank, Infrastructure for Population Studies, Faculty of Medicine, University of Oulu, Oulu, Pohjois-Pohjanmaa, Finland ${ }^{4}$ Center for Life Course Health Research, Faculty of Medicine, Medical Research Center, University of Oulu, Oulu, Pohjois-Pohjanmaa, Finland

Contributors S-PS, LH, JJ and MT were involved in the study conception and design. S-PS and LH provided study materials and collated data. All authors were involved in analysis and interpretation of the data. JJ provided statistical expertise. S-PS drafted the manuscript. LH, JA and MT revised it critically for important intellectual content. All authors approved the final version. S-PS and LH are the guarantors.

Funding The authors have not declared a specific grant for this research from any funding agency in the public, commercial or not-for-profit sectors.

Competing interests None declared.

Patient and public involvement Patients and/or the public were not involved in the design, or conduct, or reporting, or dissemination plans of this research.

Patient consent for publication Not applicable.

Ethics approval This study involves human participants and was approved by The Ethical Committee of the Northern Ostrobothnia Hospital District approved the study (\$94/2011), which was performed according to the principles of the Helsinki Declaration of 1983. The participants took part on a voluntary basis and signed their informed consent. The data were handled on a group level only, personal information being replaced by identification codes resulting in complete anonymity. Participants gave informed consent to participate in the study before taking part.

Provenance and peer review Not commissioned; externally peer reviewed.

Data availability statement Data are available in a public, open access repository. The data that support the findings of this study are available from Northern Finland Birth Cohort 1966 Study. Restrictions apply to the availability of these data, which were used under license for this study. Data are available at http://www.oulu.fi/ $\mathrm{nfbc} /$ node/44315 with the permission of Northern Finland Birth Cohort.

Open access This is an open access article distributed in accordance with the Creative Commons Attribution Non Commercial (CC BY-NC 4.0) license, which permits others to distribute, remix, adapt, build upon this work non-commercially, and license their derivative works on different terms, provided the original work is properly cited, appropriate credit is given, any changes made indicated, and the use is non-commercial. See: http://creativecommons.org/licenses/by-nc/4.0/.

ORCID iD

Suvi-Päivikki Sinikumpu http://orcid.org/0000-0001-6496-5475

\section{REFERENCES}

1 Severi G, Sinclair R, Hopper JL, et al. Androgenetic alopecia in men aged 40-69 years: prevalence and risk factors. Br J Dermatol 2003:149:1207-13.

2 Hamilton JB. Patterned loss of hair in man; types and incidence. Ann NY Acad Sci 1951;53:708-28.

3 Lolli F, Pallotti F, Rossi A, et al. Androgenetic alopecia: a review. Endocrine 2017;57:9-17.

4 Kelly Y, Blanco A, Tosti A. Androgenetic alopecia: an update of treatment options. Drugs 2016;76:1349-64.

5 Camacho FM, García-Hernández M. Psychological features of androgenetic alopecia. J Eur Acad Dermatol Venereol 2002;16:476-80.

6 Cash TF. The psychosocial consequences of androgenetic alopecia: a review of the research literature. Br J Dermatol 1999;141:398-405.

7 Budd D, Himmelberger D, Rhodes T, et al. The effects of hair loss in European men: a survey in four countries. Eur J Dermatol 2000;10:122-7.

8 Gupta S, Goyal I, Mahendra A. Quality of life assessment in patients with androgenetic alopecia. Int J Trichology 2019;11:147.

9 Williamson D, Gonzalez M, Finlay AY. The effect of hair loss on quality of life. J Eur Acad Dermatol Venereol 2001;15:137-9.

10 Tas B, Kulacaoglu F, Belli $\mathrm{H}$, et al. The tendency towards the development of psychosexual disorders in androgenetic alopecia according to the different stages of hair loss: a cross-sectional study. An Bras Dermatol 2018;93:185-90.

11 Marks DH, Penzi LR, Ibler E, et al. The medical and psychosocial associations of alopecia: recognizing hair loss as more than a cosmetic concern. Am J Clin Dermatol 2019;20:195-200.

12 Wang $X$, Xiong C, Zhang L, et al. Psychological assessment in 355 Chinese college students with androgenetic alopecia. Medicine 2018;97:e11315.

13 Wells PA, Willmoth T, Russell RJ. Does fortune favour the bald? Psychological correlates of hair loss in males. Br J Psychol 1995;86:337-44.

14 Han S-H, Byun J-W, Lee W-S, et al. Quality of life assessment in male patients with androgenetic alopecia: result of a prospective, multicenter study. Ann Dermatol 2012;24:311-8.

15 Rantakallio P. Groups at risk in low birth weight infants and perinatal mortality. Acta Paediatr Scand 1969;193:Suppl 193.

16 Sinikumpu S-P, Huilaja L, Jokelainen J, et al. High prevalence of skin diseases and need for treatment in a middle-aged population. A northern Finland birth cohort 1966 study. PLoS One 2014;9:e99533.

17 Norwood OT. Male pattern baldness: classification and incidence. South Med J 1975;68:1359-65.

18 Mattisson C, Bogren M, Horstmann V. Correspondence between clinical diagnoses of depressive and anxiety disorders and diagnostic screening via the Hopkins symptom check list-25 in the Lundby study. Nord J Psychiatry 2013;67:204-13.

19 Veijola J, Jokelainen J, Läksy K, et al. The Hopkins symptom checklist-25 in screening DSM-III-R axis-I disorders. Nord $J$ Psychiatry 2003;57:119-23.

20 Derogatis LR, Lipman RS, Covi L. SCL-90: an outpatient psychiatric rating scale-preliminary report. Psychopharmacol Bull 1973;9:13-28.

21 Sandanger I, Moum T, Ingebrigtsen G, et al. Concordance between symptom screening and diagnostic procedure: the Hopkins symptom 
checklist-25 and the composite international diagnostic interview I. Soc Psychiatry Psychiatr Epidemiol 1998;33:345-54.

22 Sandanger I, Moum T, Ingebrigtsen G, et al. The meaning and significance of caseness: the Hopkins symptom checklist-25 and the composite international diagnostic interview. II. Soc Psychiatry Psychiatr Epidemiol 1999;34:53-9.

23 Beck AT, Ward $\mathrm{CH}$, Mendelson M, et al. An inventory for measuring depression. Arch Gen Psychiatry 1961;4:561-71.

24 Steer RA, Ball R, Ranieri WF, et al. Dimensions of the beck depression Inventory-II in clinically depressed outpatients. J Clin Psychol 1999;55:117-28.

25 Lecrubier Y, Weiller E, Hergueta T. Mini international neuropsychiatric interview mini international neuropsychiatric interview, 1992.

26 Spitzer RL, Kroenke K, Williams JBW, et al. A brief measure for assessing generalized anxiety disorder: the GAD-7. Arch Intern Med 2006;166:1092-7.

27 Sintonen H, Pekurinen M. A fifteen-dimensional measure of healthrelated quality of life (15D) and its applications. In: Quality of life assessment: key issues in the 1990s. Springer, 1993: 185-95.
28 Sintonen $\mathrm{H}$. The 15D instrument of health-related quality of life: properties and applications. Ann Med 2001;33:328-36.

29 Goldberg D, Williams P. General health questionnaire (GHQ). Swindon, Wiltshire, UK: nferNelson, 2000.

30 Goldberg DP, Gater R, Sartorius N, et al. The validity of two versions of the GHQ in the WHO study of mental illness in general health care. Psychol Med 1997;27:191-7.

31 Isohanni I, Järvelin MR, Rantakallio P, et al. Juvenile and early adulthood smoking and adult educational achievements-a 31-year follow-up of the Northern Finland 1966 Birth Cohort. Scand J Public Health 2001;29:87-95.

32 Mindell JS, Giampaoli S, Goesswald A, et al. Sample selection, recruitment and participation rates in health examination surveys in Europe-experience from seven national surveys. BMC Med Res Methodol 2015;15:78-4.

33 Tanja N, Jouko M, Juha A. Cohort profile: 46 years of follow-up of theNorthern Finland birth cohort 1966 (NFBC1966). Int J Epidemiol 2021:1-12.

34 Passchier J. Quality of life issues in male pattern hair loss. Dermatology 1998;197:217-8. 